\title{
Mec1 Modulates Interhomolog Crossover and Interplays with Tel1 at Post Double-Strand Break Stages ${ }^{\text {[ }}$
}

\author{
Min-Su Lee, Jung Whan Joo, Hyungseok Choi, Hyun Ah Kang, and Keunpil Kim* \\ Department of Life Sciences, Chung-Ang University, Seoul 06974, Republic of Korea
}

\author{
Received: September 15, 2019 \\ Revised: November 27, 2019 \\ Accepted: December 1, 2019 \\ First published online: \\ December 4, 2019 \\ *Corresponding author \\ Phone: $+82-2-820-5792$ \\ Fax: +82-2-820-5206 \\ E-mail: kpkim@cau.ac.kr \\ $\mathrm{S}$ upplementary data for this \\ paper are available on-line only at \\ http://jmb.or.kr. \\ pISSN 1017-7825, eISSN 1738-8872 \\ Copyright(C) 2020 by \\ The Korean Society for Microbiology \\ and Biotechnology
}

During meiosis I, programmed DNA double-strand breaks (DSBs) occur to promote chromosome pairing and recombination between homologs. In Saccharomyces cerevisiae, Mec1 and Tel1, the orthologs of human ATR and ATM, respectively, regulate events upstream of the cell cycle checkpoint to initiate DNA repair. Tel1 ${ }^{\text {ATM }}$ and $\mathrm{Mec}^{\text {ATR }}$ are required for phosphorylating various meiotic proteins during recombination. This study aimed to investigate the role of Tel1 $1^{\mathrm{ATM}}$ and $\mathrm{Mec} \mathrm{A}^{\mathrm{ATR}}$ in meiotic prophase via physical analysis of recombination. Tel1 ${ }^{\mathrm{ATM}}$ cooperated with $\mathrm{Mec}^{\mathrm{ATR}}$ to mediate DSB-to-single end invasion transition, but negatively regulated DSB formation. Furthermore, Mec1 ${ }^{\text {ATR }}$ was required for the formation of interhomolog joint molecules from early prophase, thus establishing a recombination partner choice. Moreover, Mec1 ${ }^{\mathrm{ATR}}$ specifically promoted crossover-fated DSB repair. Together, these results suggest that $\mathrm{Te} 11^{\mathrm{ATM}}$ and $\mathrm{Mec} 1^{\mathrm{ATR}}$ function redundantly or independently in all post-DSB stages.

Keywords: Mec1, Tel1, meiosis, recombination, double-strand break

\section{Introduction}

During meiosis, duplicated chromosomes undergo recombination, wherein they exchange genetic material and form recombinants called crossovers (COs), which are essential for genetic diversity. In the first meiotic division, homologous recombination yields $\mathrm{COs}$ that are also required for appropriate chromosome segregation [1]. Premeiotic DNA replication occurs-before initiation of meiosis-yielding sister chromatids tightly held by the cohesin complex to prevent premature chromosome segregation. Parental chromosomes are aligned to form the synaptonemal complex (SC), a meiosis-specific chromosome structure playing essential roles in accurate chromosome segregation and meiotic recombination. Recombination occurs at the central regions of the SC via an association between the homologous chromosomal axis (maternal and paternal) and maturation/formation of the chromosome axis [2-4]. Meiotic recombination is initiated by programmed double-strand breaks (DSBs) generated by the type II topoisomerase-like transesterase, Spo11 [5-7], which interacts with diverse accessory factors (Rec102,
Rec104, Rec114, Mei4, Ski8, and Mer2) to regulate the cellular machinery for DSB formation [8]. Thereafter, DSBs are processed by the endonucleolytic protein complex Mre11-Rad50-Xrs2 [9, 10], and the $5^{\prime}$ ends of DSBs are further resected by Exo1, Dna2, and the Sgs1-Top3-Rmi1 complex to expose 3' single-stranded DNA tails [9], which are coated by replication protein A (RPA) complex to prevent the formation of DNA secondary structures and form nucleofilaments with RecA homologs Dmc1 and Rad51 [11-13]. These nucleofilaments containing RecA homolog-ssDNA complexes invade templates, and are stabilized in single-end invasions (SEIs) and double Holliday junctions ( $\mathrm{dHJs}$ ) and are finally processed to form crossovers (COs) $[2,13,14]$. Other species are processed as interhomolog non-crossovers (NCOs) without the exchange of flanking genes [14].

Mec1 and Tel1 in budding yeast, also known as ATR and ATM in mammals, respectively, are involved in the meiotic checkpoint network, DSB formation, and recombination [15-17]. Tel1 ${ }^{\text {ATM }}$ and Mec1 $1^{\text {ATR }}$ are serine/threonine kinases that induce phosphorylation at Ser or Thr residues preceding Gln residues, which are called SQ/TQ motifs. 
Thus, many Mec1 ${ }^{\text {ATR }}$ and Tel1 ${ }^{\text {ATM }}$ targets include SQ/TQ cluster domains (SCDs) [18]. During meiosis, Mec1 ${ }^{\text {ATR }}$ and Tel1 ${ }^{\text {ATM }}$ phosphorylate Hop1-T318 in Hop1 SCD and affect the activity of Hop1, a regulator of meiotic interhomolog recombination [17, 19]. Moreover, in budding yeast, Mec1 ${ }^{\text {ATR }}$ localizes to replication protein A (RPA)-coated ssDNA sites via Ddc2 [20]. Tel1 ${ }^{\text {ATM }}$ is activated upon DSB formation and is recruited to unresected DSBs by the MRX complex [21-23]. Moreover, phosphorylation of adaptorproteins by Tel1 ${ }^{\text {ATM }}$ and Mec1 $^{\text {ATR }}$ activates downstream effector kinases during meiosis [24]. In this study, we analyzed the roles of $\mathrm{Tel} 1^{\text {ATM }}$ and Mec1 ${ }^{\text {ATR }}$ in meiotic recombination via DNA physical analysis.

\section{Materials and Methods}

\section{Yeast Strains}

Yeast strains used herein were derived from SK1. They were homozygous for MATa/MAT $\alpha$ (Table S1). The HIS4LEU2 locus and restriction sites are shown in Fig. 1.

\section{Meiotic Time Course}

Diploid cells were plated on a YPG plate (1\% yeast extract, $2 \%$ peptone, $3 \%$ glycerol, and $2 \%$ bacto-agar) and incubated at $30^{\circ} \mathrm{C}$. Cells were streaked on a YPD plate ( $1 \%$ yeast extract, $2 \%$ peptone, $2 \%$ glucose, and $2 \%$ bacto-agar) and incubated at $30^{\circ} \mathrm{C}$. A single colony was inoculated in $2 \mathrm{ml}$ YPD liquid medium (1\% yeast extract, $2 \%$ peptone, and $2 \%$ glucose) and cultured for $24 \mathrm{~h}$ at $30^{\circ} \mathrm{C}$ $[25,26]$. To synchronize cells in the G1 stage, cultured cells were diluted 1:500 with SPS medium (1\% potassium acetate, $1 \%$ peptone, $0.5 \%$ yeast extract, $0.17 \%$ yeast nitrogen base without amino acids, $0.5 \%$ ammonium sulfate, and $0.05 \mathrm{M}$ potassium biphthalate; $\mathrm{pH}$ 5.5) and cultured for $18 \mathrm{~h}$ at $30^{\circ} \mathrm{C}$ in a shaking incubator. Synchronized cells were washed with SPM medium ( $1 \%$ potassium acetate, $0.02 \%$ raffinose, and $150 \mu \mathrm{l} / \mathrm{l}$ antifoam) at the same volume. To initiate meiosis, synchronized cells were resuspended in SPM medium and harvested at each time point and cross-linked with $0.1 \mathrm{mg} / \mathrm{ml}$ trioxalen via UV irradiation at $365 \mathrm{~nm}$ for $15 \mathrm{~min}$.

\section{DNA Physical Analysis and Southern Blotting}

Genomic DNA was extracted and physical analysis of DNA was performed as reported previously [2, 12]. For one-
A

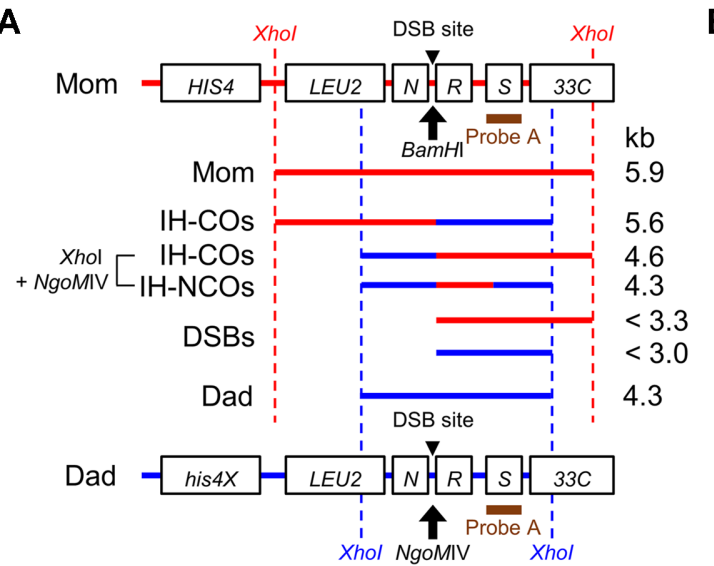

B

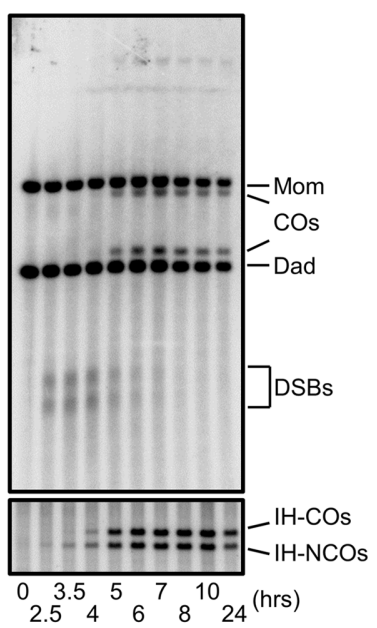

C

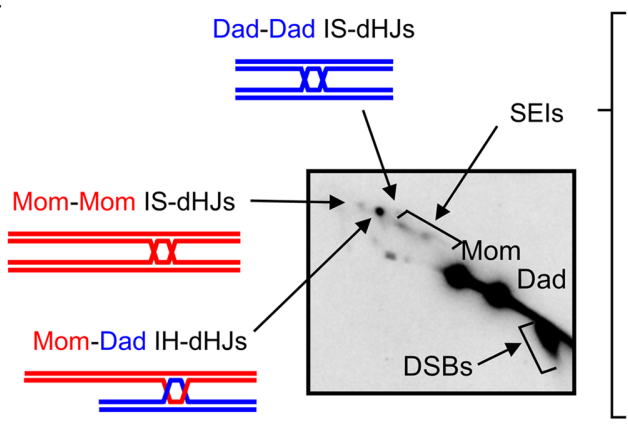

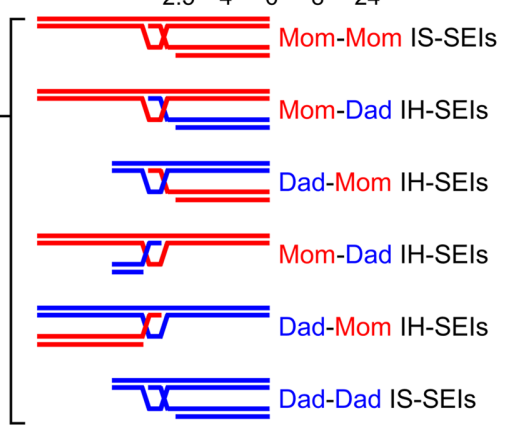

Fig. 1. Physical assay for meiotic recombination.

(A) Physical map of the HIS4LEU2 locus [2, 43]. Probe A was used to detect DNA fragments via Southern blot analysis. DSB, double-strand break; $\mathrm{CO}$, crossover; NCO, noncrossover. (B) Representative image of 1D gel analysis and CO/NCO analysis. (C) Representative image of twodimensional gel analysis. dHJs, double-Holliday junctions; SEIs, single-end invasions. 
dimensional (1D) analysis, DNA was digested with $\mathrm{XhoI}$ for $3 \mathrm{~h}$ at $37^{\circ} \mathrm{C}$. Digested DNA fragments were loaded on a $0.6 \%$ Seakem LE agarose gel - without ethidium bromide (EtBr) - prepared in TBE buffer ( $89 \mathrm{mM}$ Tris, and $2 \mathrm{mM}$ EDTA, $\mathrm{pH} 8.3$ ), and run at $\sim 2 \mathrm{~V} / \mathrm{cm}$ for $24 \mathrm{~h}$. For CO/NCO gel electrophoresis, genomic DNA was digested with $\mathrm{XhoI}$ and $\mathrm{NgoMIV}$ at $37^{\circ} \mathrm{C}$. Digested DNA fragments were loaded onto a $0.6 \%$ agarose gel. For twodimensional (2D) analysis, digested DNA fragments were loaded onto a $0.4 \%$ gold agarose gel without $\mathrm{EtBr}$ and run at $\sim 1 \mathrm{~V} / \mathrm{cm}$ for $21 \mathrm{~h}$. The gel was stained with $\operatorname{EtBr}(0.5 \mu \mathrm{g} / \mathrm{ml})$ for $30 \mathrm{~min}$, and the lanes of interest were excised and placed in a $2 \mathrm{D}$ gel tray. $2 \mathrm{D}$ gel separation was carried out using 0.8\% agarose gel containing EtBr $\left(0.5 \mu \mathrm{g} / \mathrm{ml}\right.$ ) (prepared in TBE) at $\sim 6 \mathrm{~V} / \mathrm{cm}$ for $6 \mathrm{~h}$ at $4^{\circ} \mathrm{C}$. Thereafter, the gel was treated with $0.25 \mathrm{M} \mathrm{HCl}$ for $20 \mathrm{~min}$ and with $0.4 \mathrm{M} \mathrm{NaOH}$ for $30 \mathrm{~min}$, and then transferred to Zeta-probe membrane (Bio-Rad). Southern blot analysis was carried out using ${ }^{32} \mathrm{P}$-dCTP-labeled radioactive nucleotides treated with a Random Primer Labeling Kit (Agilent Technologies). Signals corresponding to hybridized DNA fragments were detected using PhosphoImager (Bio-Rad) and quantified using Quantity One (Bio-Rad).

\section{Assessment of Meiotic Division}

Meiotic cells from SPM cultures were harvested and stored in $0.1 \mathrm{M}$ sorbitol containing $40 \%$ ethanol at $-20^{\circ} \mathrm{C}$. To visualize and count cells in meiosis I and II, cells were stained with $4^{\prime}, 6-$ diamidino-2-phenylindole (DAPI) and visualized using an Olympus BX53 fluorescence microscope (Olympus, Japan).

\section{Results and Discussion}

\section{DNA Physical Analysis for Meiotic Recombination}

Meiotic recombination intermediates were analyzed using one-dimensional (1D) and two-dimensional (2D) gel electrophoresis of the HIS4LEU2 locus, which is a wellcharacterized hot spot (Fig. 1) [2, 27-29]. Cells synchronized in the G1 phase were harvested at indicated time points. To crosslink DNA inter-strands, cells were treated with Psoralen and exposed to UV irradiation. Genomic DNA was extracted and digested with 60 units of XhoI enzyme. Digested genomic DNA fragments were separated via 1D and 2D gel analysis, followed by Southern blot hybridization (Fig. 1). DSBs were detected at $\sim 3.0$ and $\sim 3.3 \mathrm{~kb}$ via $1 \mathrm{D}$ gel electrophoresis (Figs. 1A and 1B). Joint molecules (JMs) were detected using native-native 2D gel analysis and distinguished on the basis of their conformation and molecular weight (Fig. 1C) $[2,13,27] . \mathrm{CO}$ and $\mathrm{NCO}$ products at the HIS4LEU2 locus were digested by XhoI and NgoMIV. CO and NCO were detected at $4.6 \mathrm{~kb}$ and $4.3 \mathrm{~kb}$ via $1 \mathrm{D}$ gel electrophoresis (Figs. $1 \mathrm{~A}$ and $1 \mathrm{~B})[2,14]$.

\section{Tel1 ${ }^{\text {ATM }}$ Restricts DSB Levels}

Meiotic DSBs are induced by Spo11 and its accessory factors, and repaired via recombination $[5,17]$. Tel1 ${ }^{\text {ATM }}$ suppresses clustered meiotic DSB formation and Spo11 via a negative feedback mechanism [30, 31]. Further, it has been reported that chromosome-based Tel1 ${ }^{\mathrm{ATM}}$ negatively regulates DSB formation by trans inhibition activity [30]. Thus, to investigate the roles of $\mathrm{Mec}^{\mathrm{ATR}}$ and $\mathrm{Tell}^{\mathrm{ATM}}$ in DSB formation, we assessed the recombination process via DNA physical analysis at the HIS4LEU2 hotspot on chromosome III in the absence of Mec1 $1^{\mathrm{ATR}}$ and Tel1 ${ }^{\mathrm{ATM}}$. The absence of $\mathrm{Mec}^{\mathrm{ATR}}$ causes cell death via cell cycle arrest, suppression of DNA replication, and response to DNA damage $[33,34]$. To overcome cell growth defects in the absence of $\mathrm{Mec}^{\mathrm{ATR}}$, we introduced a deletion in SML1, which decreased the resistance to DNA-damaging agents and DNA replication defects by suppressing dNTP synthesis and inhibiting interactions with ribonucleotide reductase, Rnr1, to examine the function of Mec1 ${ }^{\text {ATR }}$ [35]. In WT cells, DSBs were initiated at $2.5 \mathrm{~h}$ and peaked $(\sim 7.5 \%)$ at $3.5 \mathrm{~h}$ before gradually reducing in number. In $\operatorname{sml1} \Delta$ and sml1 $\Delta$ mec1 $1 \Delta$, DSBs were initiated at $2.5 \mathrm{~h}$ and peaked $(\sim 7 \%)$, being slightly reduced in comparison with that in WT cells; however, these mutants displayed similar DSB levels. In the absence of Tel1 ${ }^{\mathrm{ATM}}$, DSBs appeared at $2.5 \mathrm{~h}$, in a manner similar to that in WT cells, while the number of DSB at $4 \mathrm{~h}$ increased to 2 -fold $(\sim 14 \%)$ in tel1 $\Delta$ cells in comparison with that in WT cells (Figs. 2A and 2B). Through DNA physical analysis, we observed that levels of DSB at the HIS4LEU2 locus were markedly increased in the absence of Tel1 ${ }^{\text {ATM }}$. Spo11 and its accessory factors were regulated by Mec1 $1^{\text {ATR }}$ and Tel1 ${ }^{\mathrm{ATM}}$, which are required for the DNA damage response with the MRX complex [36], which in turn is involved in meiotic recombination and required for Tel1 ${ }^{\text {ATM }}$ localization at the DSB sites [21, 37-39]. Thus, high DSB levels in tel1 $\Delta$ cells may have resulted from unregulated Spo11 and MRX along with other accessory factors modulating the Spo11-oligonucletide complex at early stages of meiotic recombination.

\section{Absence of Mec1 ${ }^{\text {ATR }}$ Reduces Levels of IH-JMs}

Homologs rather than sister chromatids are preferred as templates at DSBs during meiotic recombination [2]. In contrast, the biological importance of mitotic DSB repair is inter-sister recombination. To assess the formation of JMs in the absence of $\mathrm{Mec}^{\mathrm{ATR}}$ and Tel1 ${ }^{\mathrm{ATM}}$ during meiotic recombination, we performed 2D gel analysis in each single and double mutant. In WT cells, SEIs reached 1.5\% 
A
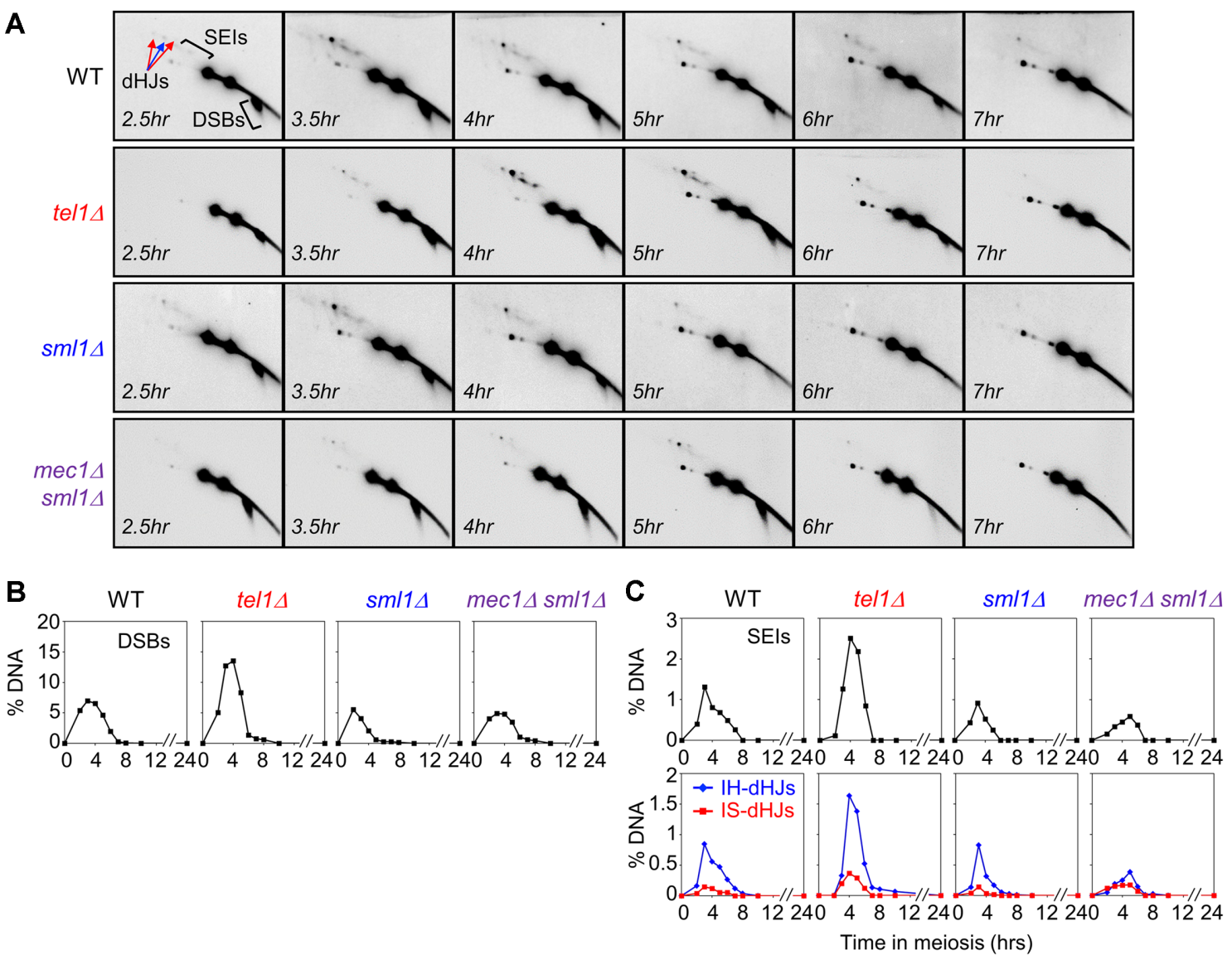

Fig. 2. Analysis of recombination intermediates in WT, tel1 1 , sml1 $\Delta$, and mec1 $\Delta$ sml1 $\Delta$ cells.

(A) 2D gel analysis at each time point in WT, tel1 1 , sml1 4 , and mec1 $\Delta$ sml1 $\Delta$ double mutant cells. (B) Quantitative analysis of DSBs during meiotic recombination. (C) Quantitative analysis of SEIs and dHJs in WT, tel14, sml14, and mec14 sml14 double mutant cells.

and the IH:IS-dHJs ratio was 5:1. In tel1 $\Delta$ cells, the levels of JMs including IH-dHJs and IS-dHJs were significantly increased in comparison with those in $\mathrm{WT}$, and the ratio of IH:IS-dHJs was 5:1 (Fig. 2). In the absence of Sml1, DSBs, SEIs, and dHJs exhibited a pattern similar to that observed in WT cells; however, in the sml1 $\Delta$ mec1 $\Delta$ strain, the level of $\mathrm{IH}-\mathrm{dHJ}$ s was reduced, while that of IS-dHJs was comparably increased. Moreover, the IH:IS-dHJ ratio was altered to $\sim 2: 1$ in the absence of Sml1 and Mec1 ${ }^{\text {ATR }}$ (Figs. 2A and 2C; Fig. S1). Thus, Mec1 ${ }^{\text {ATR }}$ promotes interhomolog interaction to form $\mathrm{IH}-\mathrm{dHJ}$, while Tel1 ${ }^{\mathrm{ATM}}$ regulates DSB formation. During meiosis, the biological imperative is inter-homolog recombination, although sister chromatids are present. To promote this phenomenon, Mec1 ${ }^{\text {ATR }}$ and its interacting proteins potentially regulate the molecular system to govern IH recombination. Hop1, an axial element protein, is a downstream target of Mec $1^{\text {ATR }}$. Phosphorylated Hop1 promotes chromosomal localization and activation of Mek1, which also promotes $\mathrm{IH}$ interaction in meiotic recombination. Therefore, Mec1-mediated Hop1 phosphorylation might promote IH formation by Rad51 activity in meiotic mode, which is regulated by Mek1 phosphorylation and recruitment.

\section{Mec $^{\text {ATR }}$ Promotes CO-Designated Recombination}

The formation of COs requires SC formation, which stabilizes the progression of IH-SEIs to promote COdesignated DSB repair. Mec1 ${ }^{\text {ATR }}$ and Tel1 ${ }^{\text {ATM }}$ phosphorylate Hop1, thus stabilizing the SC via formation of the chromosome axis [17]. To investigate whether Mec1 ${ }^{\mathrm{ATR}}$ and $\mathrm{Tel}^{\mathrm{ATM}}$ are involved in both $\mathrm{CO}$ and $\mathrm{NCO}$ recombination, we examined physical analysis of recombination in mutant strains. In WT cells, the maximum levels of $\mathrm{CO}$ and NCO species were $\sim 5 \%$ and $\sim 3.5 \%$, respectively. In the absence of Tel1 ${ }^{\mathrm{ATM}}, \mathrm{CO}$ and NCO levels increased to $\sim 6.8 \%$ and $\sim 5.5 \%$, respectively in accordance with the increase in DSB levels in comparison with levels in WT cells (Fig. 3B). In sml1 $\Delta$ mutants, the maximum levels of $\mathrm{CO}$ and $\mathrm{NCO}$ were 


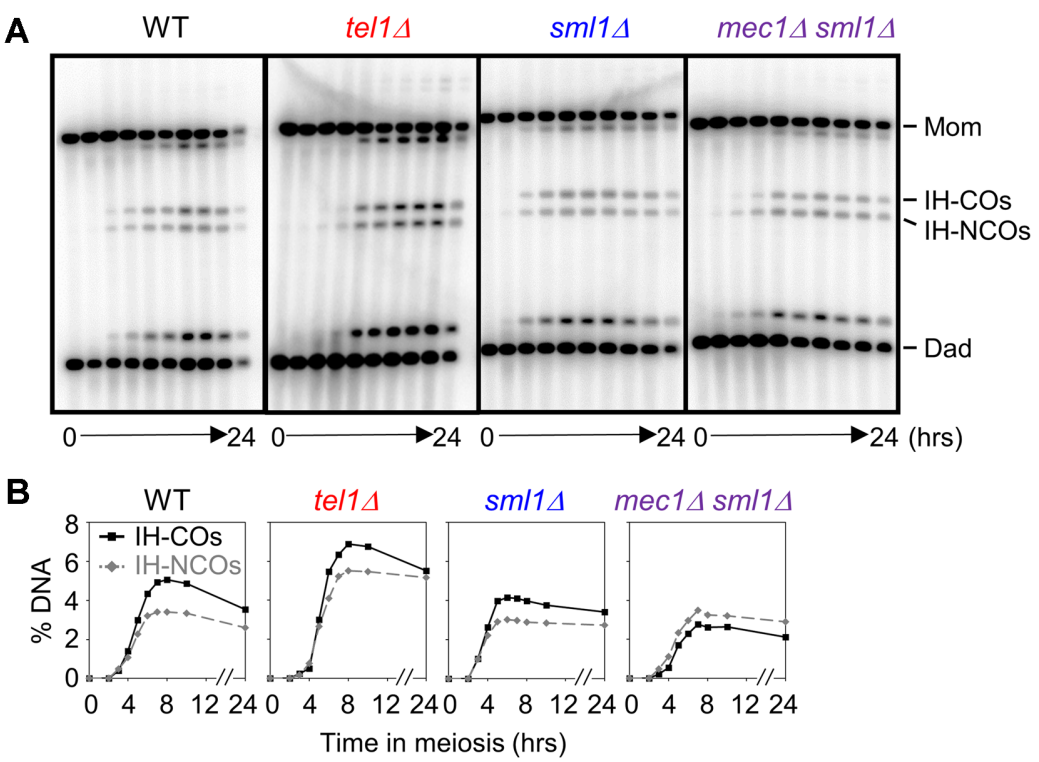

Fig. 3. Analysis of $\mathrm{CO}$ and NCO in WT, tel1 $\Delta$, sml1 $\Delta$, and mec1 $\Delta$ sml1 $\Delta$ cells.

(A) Representative $\mathrm{CO} / \mathrm{NCO}$ gel images for $\mathrm{WT}$, tel1 1 , sml1 $\Delta$, and mec1 $\Delta$ sml1 $\Delta$ double mutant cells. (B) Quantitative analysis for CO and NCO.

slightly reduced in comparison with those in WT cells; however, the CO:NCO ratio exhibited a similar pattern as shown in WT cells. In contrast, NCO levels were similar in mec1 $1 \Delta$ sml1 $\Delta$ mutant and WT cells; however, the occurrence of COs was $\sim 33 \%$ lower than that in the sml1 $\Delta$ mutant (Fig. 3). Thus, $\mathrm{Mec}^{\mathrm{ATR}}$ is specifically required for $\mathrm{CO}$ formation, but not NCO formation (Fig. 3).

\section{Mec1 $^{\text {ATR }}$ and Tel1 ${ }^{\text {ATM }}$ Cooperatively Promote the DSB-to- SEI Transition}

To assess the progress of meiotic recombination in the absence of both $\mathrm{Mec}^{\mathrm{ATR}}$ and Tel1 ${ }^{\mathrm{ATM}}$, we constructed a homogeneous $p C L B 2-T E L 1$ strain. The Tel1 ${ }^{\text {ATM }}$ promoter was replaced by the CLB2 promoter, a mitosis-specific allele activated during the mitotic cell cycle but suppressed in the meiotic cell cycle $[40,41]$. In pCLB2-TEL1 mec1A sml1 $\Delta$ mutant cells, DSBs were formed at $2.5 \mathrm{~h}$ and their levels increased significantly in comparison with those in WT cells. Moreover, DSBs were not normally resected and were retained until $24 \mathrm{~h}$ (Fig. S2). Furthermore, SEIs and $\mathrm{dHJ}$ s were not detectable upon 2D gel analysis in the pCLB2-TEL1 mec1A sml1A mutant (Fig. S2). These results suggest that $\mathrm{Mec}^{\mathrm{ATR}}$ and Tel1 ${ }^{\mathrm{ATM}}$ are both required for the DSB-to-SEI transition during meiotic recombination.

Mec1 $^{\text {ATR }}$ Promotes Recombination Independently of Rec8 The meiosis-specific $\alpha$-kleisin subunit, Rec8, is required for sister chromatid axis formation, and the formation of appropriate synaptonemal complexes (SCs) [2, 42, 43]. Moreover, Rec8 is required for maintenance of homolog bias [2, 42]. In the absence of Rec8, the ratio of IH:IS-dHJ was $\sim 1: 1$. Similarly, in the mec1 $\Delta$ mutant, the interhomolog $\mathrm{dHJ}$ were reduced; however, the intersister $\mathrm{dHJ}$ increased in the 2D gel (Fig. 2). Furthermore, we assessed the association between $\operatorname{Rec} 8$ and Mec1 in rec $8 \Delta$ sml1 $\Delta$ and

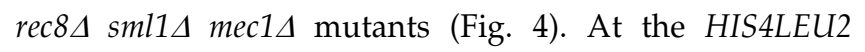
hotspot, both rec $8 \Delta$ sml1 $\Delta$ and rec $8 \Delta$ sml1 $\Delta$ mec1 $\Delta$ mutant displayed reduced DSB levels (Fig. 4B). Moreover, in the rec8 $\Delta$ sml14 mec1 1 mutant, DSB turnover was delayed relative to that in the sml1 $\Delta$ mec1 $\Delta$ mutant (Fig. 4B). The IH:IS ratio in rec $8 \Delta \operatorname{sml} 1 \Delta$ and rec $8 \Delta$ sml1 $\Delta$ mec $1 \Delta$ mutants was 1:1 (IH:IS dHJs), consistent with the rec $8 \Delta$ mutant phenotypes (Fig. 4B) [2]. Further, the rec8 $\Delta$ sml1 $\Delta$ mec1 $\Delta$ mutant exhibited a reduction in the levels of $\mathrm{CO}$ and $\mathrm{NCO}$ (Figs. 4C and 4D). Thus, Mec1 ${ }^{\text {ATR }}$ contributes to post-DSB stages independent of Rec 8 during meiotic recombination.

$\mathrm{Mec}^{\mathrm{ATR}}$ and Tel1 ${ }^{\mathrm{ATM}}$ function in the DNA damage response, cell cycle checkpoint, and meiotic recombination. The present results elucidate the roles of $\mathrm{Tel1}^{\mathrm{ATM}}$ in restriction of DSB formation and $\mathrm{Mec}^{\mathrm{ATR}}$ in CO-specific recombination at post-DSB stages during meiotic prophase. However, further studies are required to define the meiosis-specific effects of $\mathrm{Mec}^{\mathrm{ATR}}$ and Tel1 ${ }^{\mathrm{ATM}}$ during recombination and chromosome dynamics. 
A
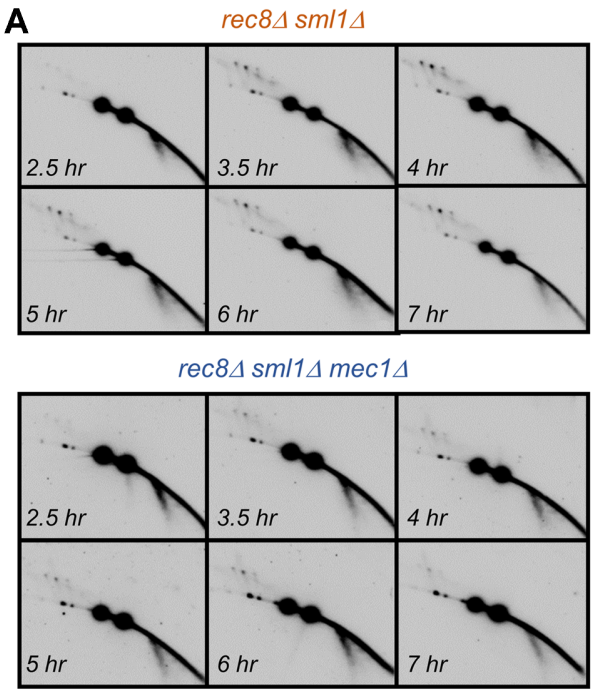

C

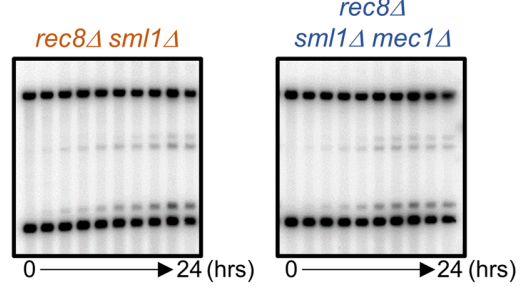

B

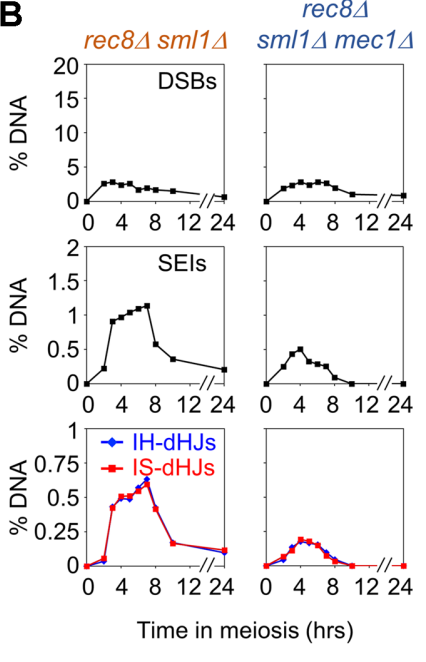

D

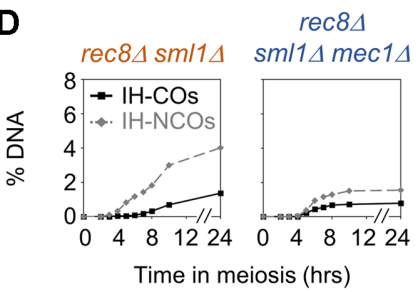

Fig. 4. Cohesin-independent role of Mec1 in meiotic recombination.

(A) Representative images of 2D gel analysis for rec8 $\Delta$ sml1 $\Delta$ and rec8 8 sml1 $\Delta$ mec1 $1 \Delta$. (B) Quantitative analysis of DSBs, SEIs, IH-dHJs, and IS-dHJs

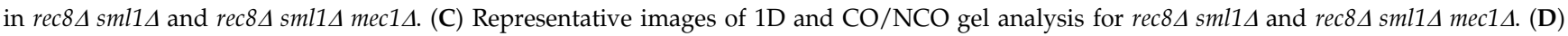
Quantitative analysis of CO and NCO.

\section{Acknowledgements}

This study was supported by grants from the National Research Foundation of Korea (NRF) grant funded by the Korea government (MSIT) (2018R1A5A1025077) and the Chung-Ang University Graduate Research Scholarship in 2019.

\section{Conflict of Interest}

The authors have no financial conflicts of interest to declare.

\section{References}

1. Kleckner N, Zhang L, Weiner B, Zickler D. 2011. In genome organization and function in the cell nucleus, Chapter 19, K. Rippe, ed. (Weinheim, Germany: Wiley-VCH).

2. Kim KP, Weiner BM, Zhang L, Jordan A, Dekker J, Kleckner N. 2010. Sister cohesion and structural axis components mediate homolog bias of meiotic recombination. Cell 143: 924-937.
3. Sanchez-Moran E, Santos JL, Jones GH, Franklin FC. 2007. ASY1 mediates AtDMC1-dependent interhomolog recombination during meiosis in Arabidopsis. Genes Dev. 21: 2220-2233.

4. Lao JP, Hunter N. 2010. Trying to avoid your sister. PLoS Biol. 8: e1000519

5. Keeney S, Giroux C, Kleckner N. 1997. Meiosis-specific DNA double-strand breaks are catalyzed by Spo11, a member of a widely conserved protein family. Cell 88: 375-384.

6. Keeney S. 2001. Mechanism and control of meiotic recombination initiation. Curr. Top. Dev. Biol. 52: 1-53.

7. Neale MJ, Pan J, Keeney S. 2005. Endonucleolytic processing of covalent protein-linked DNA double-strand breaks. Nature 436: 1053-1057.

8. Murakami H, Keeney S. 2008. Regulating the formation of DNA double-strand breaks in meiosis. Genes Dev. 22: 286292.

9. Cannavo E, Cejka P. 2014. Sae2 promotes dsDNA endonuclease activity within Mre11-Rad50-Xrs2 to resect DNA breaks. Nature 514: 122-125.

10. Garcia V, Phelps SE, Gray S, Neale MJ. 2011. Bidirectional resection of DNA double-strand breaks by Mre11 and Exo1. Nature 479: 241-244. 
11. Ribeiro J, Abby E, Livera G, Martini E. 2016. RPA homologs and ssDNA processing during meiotic recombination. Chromosoma 125: 265-276.

12. Sasanuma H, Tawaramoto MS, Lao JP, Hosaka H, Sanda E, Suzuki M, et al. 2013. A new protein complex promoting the assembly of Rad51 filaments. Nat. Commun. 4: 1676.

13. Hong S, Kim KP 2013. Shu1 promotes homolog bias of meiotic recombination in Saccharomyces cerevisiae. Mol. Cells 36: 446-454.

14. Borner GV, Kleckner N, Hunter N. 2004. Crossover/ noncrossover differentiation, synaptonemal complex formation, and regulatory surveillance at the leptotene/zygotene transition of meiosis. Cell 117: 29-45.

15. Grushcow JM, Holzen TM, Park KJ, Weinert T, Lichten M, Bishop DK. 1999. Saccharomyces cerevisiae checkpoint genes MEC1, RAD17 and RAD24 are required for normal meiotic recombination partner choice. Genetics 153: 607-620.

16. Thompson D, Stahl F 1999. Genetic control of recombination partner preference in yeast meiosis: isolation and characterization of mutants elevated for meiotic unequal sister-chromatid recombination. Genetics 153: 621-641.

17. Carballo JA, Johnson AL, Sedgwick SG, Cha RS. 2008. Phosphorylation of the axial element protein Hop1 by Mec1/Tel1 ensures meiotic interhomolog recombination. Cell 132: $758-770$.

18. Traven A, Heierhorst J. 2005. SQ/TQ cluster domains: concentrated ATM/ATR kinase phosphorylation site regions in DNA-damage-response proteins. Bioessays 27: 397-407.

19. Chuang CN, Cheng YH, Wang TF. 2012. Mek1 stabilizes Hop1-Thr318 phosphorylation to promote interhomolog recombination and checkpoint responses during yeast meiosis. Nucleic Acids Res. 40: 11416-11427.

20. Navadgi-Patil VM, Burgers PM. 2009. A tale of two tails: activation of DNA damage checkpoint kinase Mec1/ATR by the 9-1-1 clamp and by Dpb11/TopBP1. DNA Repair (Amst) 8: 996-1003.

21. Falck J, Coates J, Jackson SP 2005. Conserved modes of recruitment of ATM, ATR and DNA-PKcs to sites of DNA damage. Nature 434: 605-611

22. Usui T, Ogawa H, Petrini JH. 2001. A DNA damage response pathway controlled by Tel1 and the Mre11 complex. Mol. Cell 7: 1255-1266.

23. You Z, Chahwan C, Bailis J, Hunter T, Russell P. 2005. ATM activation and its recruitment to damaged DNA require binding to the $\mathrm{C}$ terminus of Nbs1. Mol. Cell Biol. 25: 5363-5379.

24. Melo J, Toczyski D. 2002. A unified view of the DNAdamage checkpoint. Curr. Opin. Cell Biol. 14: 237-245.

25. Choi HJ, Kim YH. 2018. Simultaneous and sequential integration by Cre/loxP site-specific recombination in Saccharomyces cerevisiae. J. Microbiol. Biotechnol. 28: 826-830.

26. Jing H, Liu H, Zhang L, Gao J, Song H, Tan X. 2018. Ethanol induces autophagy regulated by mitochondrial ROS in Saccharomyces cerevisiae. J. Microbiol. Biotechnol. 28: 1982-1991.
27. Hunter N, Kleckner N. 2001. The single-end invasion: an asymmetric intermediate at the double-strand break to double-Holliday junction transition of meiotic recombination. Cell 106: 59-70.

28. Hong S, Sung Y, Yu M, Lee M, Kleckner N, Kim KP. 2013. The logic and mechanism of homologous recombination partner choice. Mol. Cell 51: 440-453.

29. Lee MS, Yoon SW, Kim KP. 2015. Mitotic cohesin subunit Mcd1 regulates the progression of meiotic recombination in budding yeast. J. Microbiol. Biotechnol. 25: 598-605.

30. Lange J, Pan J, Cole F, Thelen MP, Jasin M, Keeney S. 2011. ATM controls meiotic double-strand-break formation. Nature 479: $237-240$

31. Garcia V, Gray S, Allison RM, Cooper TJ, Neale MJ. 2015. Tel1(ATM)-mediated interference suppresses clustered meiotic double-strand-break formation. Nature 520: 114-118.

32. Zhang L, Kim KP, Kleckner NE, Storlazzi A 2011. Meiotic double-strand breaks occur once per pair of (sister) chromatids and, via Mec1/ATR and Tel1/ATM, once per quartet of chromatids. Proc. Natl. Acad. Sci. USA 108: 20036-20041.

33. Kato R, Ogawa 1994. An essential gene, ESR1, is required for mitotic cell growth, DNA repair and meiotic recombination in Saccharomyces cerevisiae. Nucleic Acids Res. 22: 3104-3012.

34. Carr AM. 1997. Control of cell cycle arrest by the Mec1sc/ Rad3sp DNA structure checkpoint pathway. Curr. Opin. Genet. Dev. 7: 93-98.

35. Zhao X, Muller EG, Rothstein R 1998. A suppressor of two essential checkpoint genes identifies a novel protein that negatively affects dNTP pools. Mol. Cell 2: 329-340.

36. Grenon M, Magill CP, Lowndes NF, Jackson SP. 2006 Double-strand breaks trigger MRX- and Mec1-dependent, but Tel1-independent, checkpoint activation. FEMS Yeast Res. 6: 836-847.

37. Uziel T, Lerenthal Y, Moyal L, Andegeko Y, Mittelman L, Shioh Y. 2003. Requirement of the MRN complex for ATM activation by DNA damage. EMBO J. 22: 5612-5621.

38. Mohibullah N, Keeney S. 2017. Numerical and spatial patterning of yeast meiotic DNA breaks by Tell. Genome Res. 27: 278-288.

39. Beyer T, Weinert T. 2014. Mec1 and Tel1: an arresting dance of resection. EMBO J. 33: 176-178.

40. Lee BH, Amon A. 2003. Role of Polo-like kinase CDC5 in programming meiosis I chromosome segregation. Science 300: $482-486$

41. Jin H, Guacci, V, Yu HG. 2009. Pds5 is required for homologue pairing and inhibits synapsis of sister chromatids during yeast meiosis. J. Cell Biol. 186: 713-725.

42. Yoon SW, Lee MS, Xaver M, Zhang L, Hong SG, Kong YJ, et al. 2016. Meiotic prophase roles of Rec8 in crossover recombination and chromosome structure. Nucleic Acids Res. 44: 9296-9314.

43. Hong S, Joo JH, Yun H, Kim K. 2019. The nature of meiotic chromosome dynamics and recombination in budding yeast. J. Microbiol. 57: 221-231. 